\title{
Tomatoes Maturation Analysis with Reflectance Spectral Images
}

Julia Lopes Governici ${ }^{1}$, Rodrigo Magalhães Faria ${ }^{2}$, Rodolpho César dos Reis Tinini ${ }^{3}$ and Barbara Janet Teruel Mederos ${ }^{4}$

1. Department of Agricultural Engineering, Federal University of Viçosa, Viçosa, Minas Gerais 36570-000, Brazil

2. Department of Plant Science, Federal University of Viçosa, Viçosa, Minas Gerais 36570-000, Brazil

3. Agricultural Sciences Institute, Federal University of Minas Gerais, Montes Claros, Minas Gerais 39404-547, Brazil

4. College of Agricultural Engineering, The State University of Campinas, Campinas, São Paulo 13083-875, Brazil

\begin{abstract}
The demands for high quality products are increasing in the market, so several tests are performed. These analyses are destructive, time consuming and sometimes expensive. The spectral imaging technique is an alternative that can reduce costs and time and increase the efficiency and cost-effectiveness of these analyses. In this context, the aim of this study was to verify the spectral behavior of the tomato in function of the maturation and its potential use for non-destructive evaluation of food quality. Eighty tomatoes of the Italian group were selected in four stages of maturation (green, pink, light red and red). Images were collected in wavelengths $480 \mathrm{~nm}$ to $710 \mathrm{~nm}$ (every $10 \mathrm{~nm}$ ). After the images were collected, the fruits were submitted to the physical-chemical analyses. The following parameters were analyzed: color, color index (CI), pH, soluble solids (SS), total titratable acidity (TTA) and ratio (SS/TTA). After characterization the mean spectrum was obtained by the extraction of the spectral characteristics. It was observed that the spectral behavior was the same for all stages of maturation. It was possible to differentiate the green tomatoes in the wavelengths from $520 \mathrm{~nm}$ to $560 \mathrm{~nm}$ and from $610 \mathrm{~nm}$ to $660 \mathrm{~nm}$. These intervals represent the area of reflection of chlorophyll and lycopene, respectively. Near the wavelength $560 \mathrm{~nm}$, the highest absorbance was recorded by ripe tomatoes due to the concentration of lycopene. It is concluded that the best wavelengths for analysis are those in which green has the highest reflectance and it is possible to apply this technique for non-destructive analysis of the maturation of tomatoes.
\end{abstract}

Key words: Non-destructive analysis, mean spectrum, physical-chemical analysis, Solanum lycopersicum.

\section{Introduction}

Currently, tomato is considered one of the most important vegetables in the world. In 2012, China was the largest tomato producer and Brazil ranked eighth in the world [1]. The tomato for processing depends on several characteristics and good quality. Laboratory tests are performed to ensure nutritional and health standards. These tests are destructive, time consuming, and sometimes expensive chemical reagents and equipment are required, which makes the procedure very costly. As a result, studies are being conducted to look for faster, more accurate and more cost-effective data acquisition methods and tools.

Corresponding author: Bárbara Janet Teruel Mederos, Ph.D., research field: agricultural machinery.
Recent technological advances have increased the potential of light-tissue interaction in studies of photosynthetic activity and chlorophyll content in plants [2], monitoring of product quality and safety [3, 4] and detection of plant injuries [5, 6], maturity stages [7], physical characteristics and chemical components, such as sugar content [8-10].

One such technique, spectral imaging, can be used as an alternative to improve control of tomato processing, reduce costs and ensure quality products to the consumer. This technique generates spatial maps that allow the identification and distribution of several sample components and can be applied for various purposes [11]. However, for tomatoes, it is necessary to select and define the best spectral bands and the most appropriate way to develop the image 
acquisition and processing system.

In this context, the objective of this work was to verify the spectral behavior of the tomato in function of the degree of maturation and its potential use for non-destructive evaluation of food quality.

\section{Materials and Methods}

\subsection{Samples and Physical-Chemical Analysis}

The samples were obtained from a fruit and vegetable distribution center in the city of Montes Claros-Minas Gerais, Brazil. Eighty tomatoes of the Italian group were selected in four stages of maturation (green, pink, light red and red).

The physical-chemical characteristics analyzed were color, color index (CI) [12], pH, soluble solids (SS), total titratable acidity (TTA) [13] and ratio (SS/TTA).

Only SS data presented normal distribution and were analyzed by the Tukey test at $1 \%$ significance. The other characteristics, which presented abnormal distribution, were submitted to the Kruskal-Wallis test at $1 \%$ significance level. The software used for statistical analysis was R.

\subsection{System and Acquisition of Images}

The image acquisition system was composed of monochromatic charged couple camera (CCD), model mvBlueFOX-223G Matrix Vision, Germany, filter wheel (model FW102B, Thorlabs, USA), $25 \mathrm{~mm}$ objective lens and light emitting diodes high-power white (LEDs) to promote the excitation source of the spectral images. In addition, for image acquisition and lighting control, an Arduino ${ }^{\circledR}$ Uno was used.

The images were captured using wavelengths between $480 \mathrm{~nm}$ and $710 \mathrm{~nm}$ (models from FB480-10 to FB710-10, Thorlabs, USA), every $10 \mathrm{~nm}$ to obtain spectral response of the product at different wavelengths. Therefore, 24 images were captured for each sample, totaling 1,920 images.

\subsection{Data Processing}

After collecting the images, to facilitate the following analyses, they were processed through operations aimed at improving the visibility of the characteristics of interest and correcting defects of light scattering and possible noise [14, 15].

The images were first normalized according to the camera and optical filter transmission curves. After normalization, the regions of interest (ROIs) were highlighted manually.

A dataset composed of a matrix was created, in which the lines present the pixel values and the columns the wavelength for each stage of maturation of the tomato. Once the dataset was done, the spectral data were preprocessed.

In order to reduce environmental and texture effects, known as additive and multiplicative effects, and to smooth noise, the data were preprocessed using a relative normalization. The relative normalization consists of calculating the sum of the spectrum and then subtracting from the mean and dividing by the sum of each value of the spectrum. Thus, the spectral scattering effect was removed and, therefore, a normalized dataset was obtained [16].

From the normalized dataset, the mean spectrum of each maturation stage of the tomato samples was obtained from the mean and standard deviation of the wavelengths.

The image analysis was performed with the help of MATLAB $^{\circledR}$ software.

\section{Results and Discussion}

\subsection{Chemical Characteristics at Different Maturation Stages}

It was observed that SS and SS/TTA values are in high quality fruit standards as stipulated by Mencarelli and Saltveit Jr. [17]. However, tomatoes classified as light red and red had lower TTA values than the ideal one (Table 1). These characteristics directly interfere 
with the taste of the product and the use of additives in processing, so they should be analyzed together. The tomatoes showed $\mathrm{pH}$ around 4.0, which is common for this fruit [18-20].

\subsection{Color Parameters at Different Maturation Stages}

The only color parameter that was not influenced by maturation was $b^{*}$, which represents the color variation from yellow to blue (Table 2). In relation to the luminosity $\left(L^{*}\right)$, green tomatoes presented the highest value and there was no difference between light red and red tomatoes. This is due to the concentration of chlorophyll and lycopene in the green and mature fruits, respectively. There is a negative correlation between lycopene and this color parameter, so with the advancement of maturation the tendency of $L^{*}$ is decreased [21, 22]. During the ripening of the tomato, there is intense degradation of chlorophyll and lycopene synthesis [23]. When the compounds being responsible for the red color, mainly lycopene, begin to be synthesized, the value of $L^{*}$ decreases, indicating darkening of the fruit [24].

The behavior observed for the variable $a^{*}$ (variation from green to red) was the same as for the CI variable. As the tomatoes mature, the values of $a^{*}$ and CI increased, however the values for light red and red tomatoes are the same. During tomato maturation, the variation from green to red $\left(a^{*}\right)$ is intense and ends up masking the other parameters of the CI [24]. Lycopene is also related to $a^{*}$, so the increase in the values of $a^{*}$ indicates higher lycopene contents [21].

\subsection{Spectral Behavior at Different Maturation Stages}

The difficulty of differentiating light red and red tomatoes was also observed in the reflectance mean spectrum (Fig. 1), which confirmed the relationship between reflectance and physical-chemical characteristics. From $520 \mathrm{~nm}$ to $560 \mathrm{~nm}$ and from 610 $\mathrm{nm}$ to $660 \mathrm{~nm}$, only green tomatoes can be distinguished. This behavior is related to the spectral areas of reflection and absorbance of chlorophyll, respectively.

Liu et al. [25] also observed a region of low reflectance near $660 \mathrm{~nm}$ due to the absorption of chlorophyll. Clément et al. [26] observed a peak of reflectance for green tomatoes between $550 \mathrm{~nm}$ and $560 \mathrm{~nm}$, because in this region there is no absorption by chlorophyll. Near $680 \mathrm{~nm}$ was observed that the absorption was related to the green coloration of the fruits, which was influenced by the chlorophyll content [26, 27].

It is noted that at wavelengths $560,580,630,640$,

Table 1 Chemical characteristic at different maturation stages.

\begin{tabular}{lllll}
\hline \multirow{2}{*}{ Maturation } & \multicolumn{3}{c}{ Chemical characteristics } \\
\cline { 2 - 5 } & $\mathrm{pH}^{2}$ & $\mathrm{SS}^{1}(\%)$ & $\mathrm{TTA}^{2}(\%)$ & Ratio $^{2}$ \\
\hline Green & $4.32 \pm 0.40^{\mathrm{a}}$ & $4.69 \pm 0.36^{\mathrm{a}}$ & $0.36 \pm 0.09^{\mathrm{a}}$ & $14.01 \pm 5.30^{\mathrm{abc}}$ \\
Pink & $4.11 \pm 0.05^{\mathrm{b}}$ & $4.30 \pm 0.33^{\mathrm{b}}$ & $0.35 \pm 0.04^{\mathrm{a}}$ & $12.45 \pm 1.39^{\mathrm{c}}$ \\
Light red & $4.19 \pm 0.07^{\mathrm{a}}$ & $4.53 \pm 0.37^{\mathrm{ab}}$ & $0.30 \pm 0.03^{\mathrm{b}}$ & $15.08 \pm 2.45^{\mathrm{ab}}$ \\
Red & $4.25 \pm 0.09^{\mathrm{a}}$ & $4.51 \pm 0.21^{\mathrm{ab}}$ & $0.29 \pm 0.02^{\mathrm{b}}$ & $15.39 \pm 1.12^{\mathrm{a}}$ \\
\hline
\end{tabular}

${ }^{1}$ Means followed by the same letter in column do not differ by Tukey's test at $p<0.01$, CV $=7.2 \%$.

${ }^{2}$ Means followed by the same letter in column do not differ by Kruskal-Wallis's test at $p<0.01$.

Table 2 Color parameters at different maturation stages.

\begin{tabular}{|c|c|c|c|c|}
\hline \multirow{2}{*}{ Maturation } & \multicolumn{4}{|c|}{ Color parameters } \\
\hline & $L^{*}$ & $a^{*}$ & $b^{*}$ & CI \\
\hline Green & $52.46 \pm 2.41^{\mathrm{a}}$ & $-8.89 \pm 2.01^{\mathrm{C}}$ & $22.53 \pm 4.98^{\mathrm{a}}$ & $-14.11 \pm 0.38^{\mathrm{c}}$ \\
\hline Pink & $43.59 \pm 1.52^{\mathrm{b}}$ & $11.62 \pm 2.64^{b}$ & $24.69 \pm 2.30^{\mathrm{a}}$ & $19.46 \pm 0.19^{b}$ \\
\hline Light red & $38.18 \pm 1.00^{c}$ & $21.75 \pm 1.42^{\mathrm{a}}$ & $23.66 \pm 2.18^{\mathrm{a}}$ & $35.49 \pm 0.19^{a}$ \\
\hline Red & $36.90 \pm 0.46^{\mathrm{c}}$ & $23.47 \pm 1.44^{\mathrm{a}}$ & $23.25 \pm 1.18^{\mathrm{a}}$ & $38.49 \pm 0.13^{\mathrm{a}}$ \\
\hline
\end{tabular}

Means followed by the same letter in column do not differ by Kruskal-Wallis's test at $p<0.01$. 
$650 \mathrm{~nm}$, the reflectance spectra follow an order according to maturation. Liu et al. [25] also obtained a graph in which it was possible to observe this arrangement in some wavelengths. This can be explained by the variation in the concentration of chlorophyll and lycopene throughout the maturation, which influences the reflectance of the tomato.

The spectral behavior was similar for the maturation stages, with the exception of the interval between $600 \mathrm{~nm}$ and $620 \mathrm{~nm}$, where the reflectance of green tomatoes decreases and that of the others increases. The reflectance peaks at wavelengths 560 $\mathrm{nm}$ and $580 \mathrm{~nm}$, spectral regions of green, occuring due to chlorophyll reflectance and lycopene absorbance, compounds present in higher concentrations in green and mature fruits, respectively. At $620 \mathrm{~nm}$ of spectral region of red, there is a reflectance of lycopene and chlorophyll absorbance [28], which explains the higher reflectance obtained for fruits with more advanced maturation.

Among the wavelengths $510 \mathrm{~nm}$ and $580 \mathrm{~nm}$ of chlorophyll reflection region [26, 29], the highest reflectance value is presented by green tomatoes and the lowest by light red and red tomatoes. Between $610 \mathrm{~nm}$ and $660 \mathrm{~nm}$, the behavior is the opposite; the highest values are observed for tomatoes with advanced maturation stage and the lowest for green tomatoes.

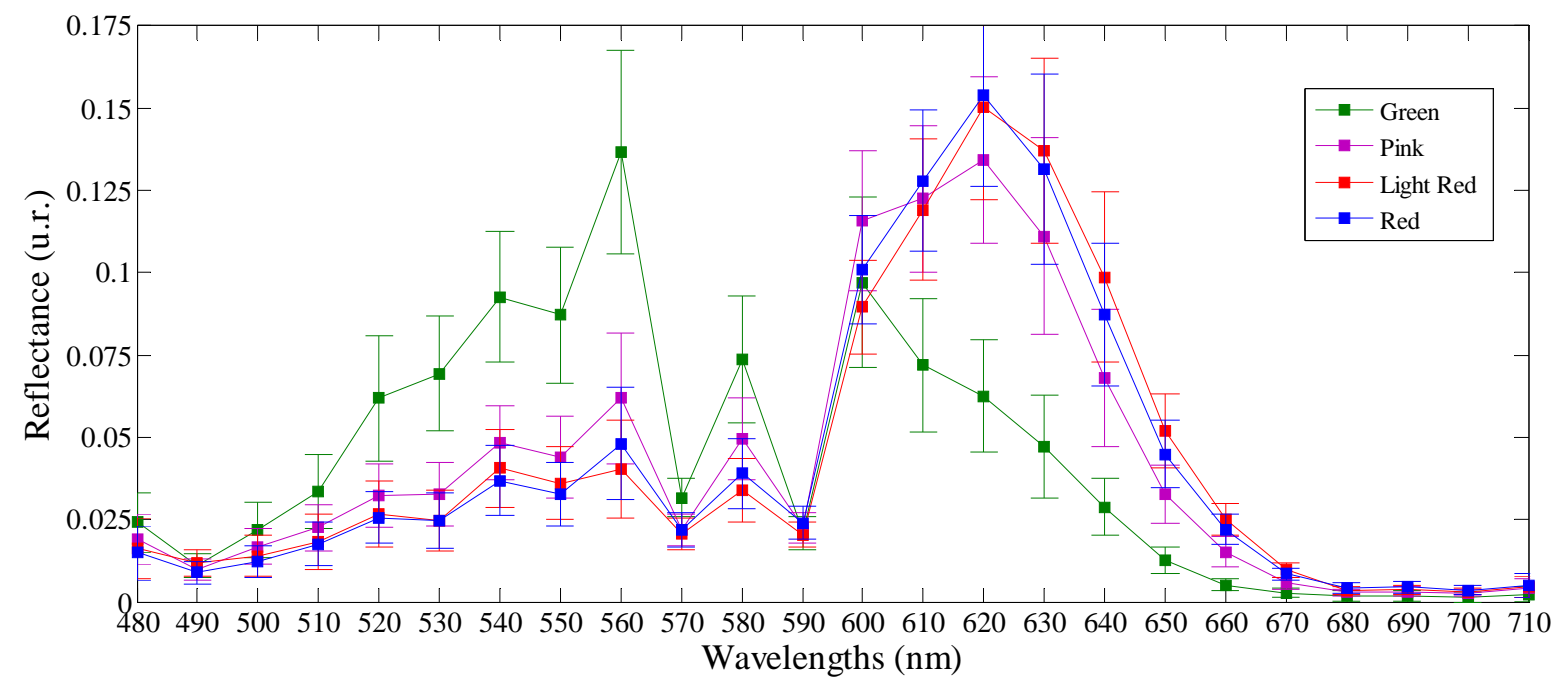

Fig. 1 Reflectance mean spectrum of each maturation stage of the tomato.

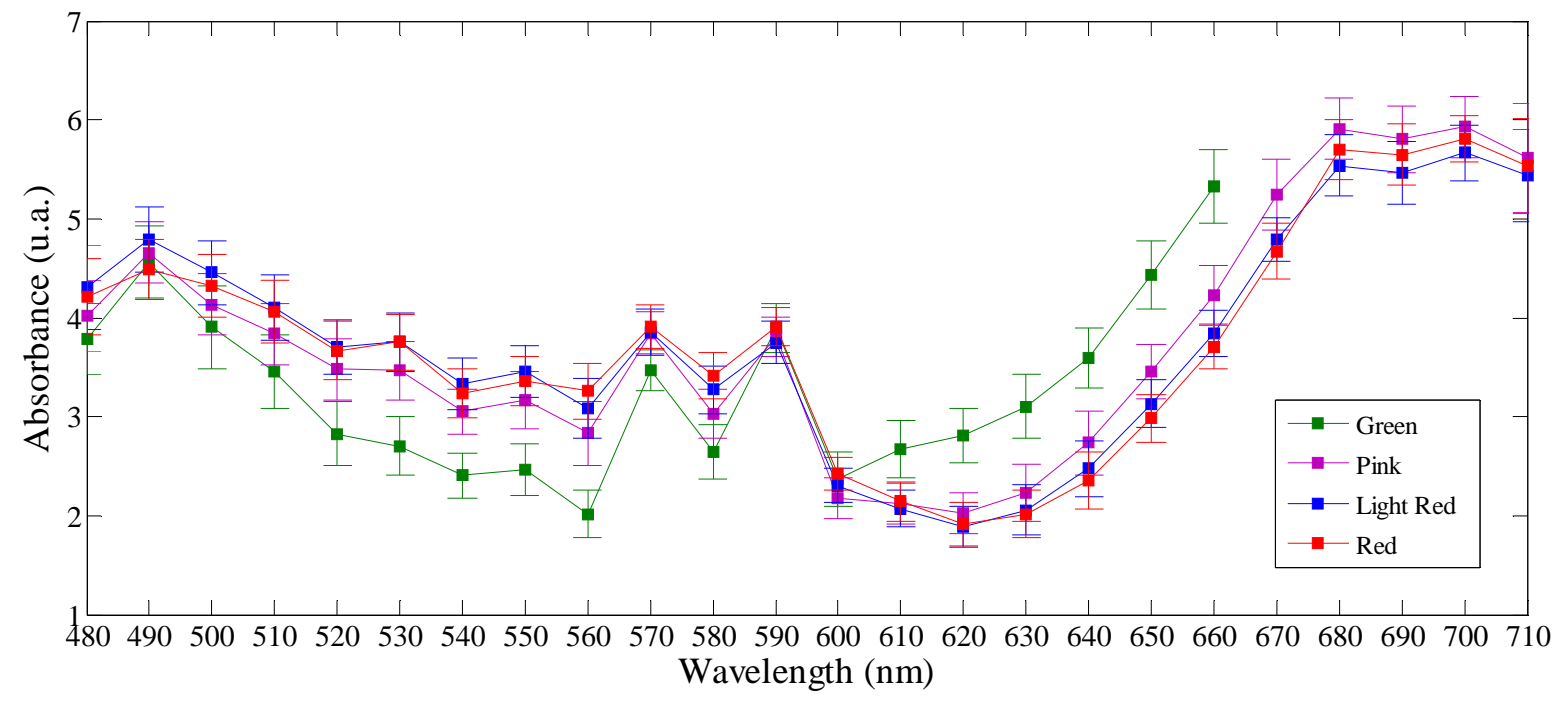

Fig. 2 Absorbance mean spectrum of each maturation stage of the tomato. 
At the wavelength $565 \mathrm{~nm}$, the highest absorbance was recorded by mature tomatoes (Fig. 2), as it is in this region that there is high absorbance of lycopene in aqueous medium [28].

The images of reflectance were efficient to differentiate green tomatoes from the others, but it was not possible to distinguish graphically tomatoes with more advanced maturation, which can be possible through multivariate analysis and using other sources of illumination. It is verified that the spectral response of the fruit depends on its chemical characteristics, mainly chlorophyll and lycopene content, which give green and red color to the fruits, respectively. These characteristics are evidenced in the reflection and absorption peaks of chlorophyll and lycopene. Therefore, the technique is applicable to determine the maturation of the fruits, but other techniques of analysis must be combined to apply spectral images in the evaluation of food quality.

\section{Conclusions}

The spectral behavior of tomato is related to the maturation of the fruit. Green tomatoes showed higher reflectance between wavelengths $520 \mathrm{~nm}$ and $560 \mathrm{~nm}$. On the other hand, mature tomatoes presented higher reflectance between the wavelengths $610 \mathrm{~nm}$ and 660 $\mathrm{nm}$. This knowledge is very important to improve the control of tomato processing, reduce costs and ensure quality products in a non-destructive way. The tomatoes follow a spectral pattern independent of the maturation stage, and the best wavelengths to distinguish green tomatoes are from $520 \mathrm{~nm}$ to 560 $\mathrm{nm}$ and from $610 \mathrm{~nm}$ to $660 \mathrm{~nm}$. However, it may be that multivariate analysis techniques can determine the other stages of maturation. Therefore, it is possible to use spectral images for non-destructive evaluation of tomato maturation, but for the method to be applied for analysis of food quality, other techniques must be used together.

\section{Acknowledgments}

Sincere thanks are expressed to College of Agricultural Engineering at the State University of Campinas (FEAGRI/UNICAMP) and Federal University of Minas Gerais (ICA/UFMG) for the support to the experimentation.

\section{References}

[1] Food and Agriculture Organization of the United Nations (FAO). 2012. Statistics Division. Acessed March 28, 2016. http://faostat.fao.org/site/339/default.aspx.

[2] Lenk, S., Chaerle, L., Pfündel, E. E., Langsdorf, G., Hagenbeek, D., Lichtenthaler, H. K., Van Der Straeten, D., and Buschmann, C. 2007. "Multispectral Fluorescence and Reflectance Imaging at the Leaf Level and Its Possible Applications.” Journal of Experimental Botany 58 (4): 807-14.

[3] ElMasry, G., Wang, N., ElSayed, A., and Ngadi, M. 2007. "Hyperspectral Imaging for Non-destructive Determination of Some Quality Attributes for Strawberry." Journal of Food Engineering 81 (1): 98-107.

[4] Gowen, A. A., Tiwari, B. K., Cullen, P. J., McDonnell, K., and O’Donnell, C. P. 2010. “Applications of Thermal Imaging in Food Quality and Safety Assessment.” Trends in Food Science and Technology 21 (4): 190-200.

[5] ElMasry, G., Wang, N., and Vigneault, C. 2009. "Detecting Chilling Injury in Red Delicious Apple Using Hyperspectral Imaging and Neural Networks.” Postharvest Biology and Technology 52 (1): 1-8.

[6] Pan, L., Zhang, Q., Zhang, W., Sun, Y., Hu, P., and Tu, K. 2016. "Detection of Cold Injury in Peaches by Hyperspectral Reflectance Imaging and Artificial Neural Network.” Food Chemistry 192: 134-41.

[7] Rajkumar, P., Wang, N., EImasry, G., Raghavan, G. S. V., and Gariepy, Y. 2012. "Studies on Banana Fruit Quality and Maturity Stages Using Hyperspectral Imaging." Journal of Food Engineering 108 (1): 194-200.

[8] Lou, H., Hu, Y., Zhang, L., Sun, P., and Lu, H. 2012. "Non-destructive Evaluation of the Changes of Total Flavonoid, Total Phenols, ABTS and DPPH Radical Scavenging Activities, and Sugars during Mulberry (Morus alba L.) Fruits Development by Chlorophyll Fluorescence and RGB Intensity Values.” LWT_Food Science and Technology 47 (1): 19-24. 
[9] Gonzálvez, A. G., Martínez, N. L., Telle, H. H., and Ureña, Á. G. 2013. "Monitoring LED-Induced Carotenoid Increase in Grapes by Transmission Resonance Raman Spectroscopy.” Chemical Physics Letters 559: 26-9.

[10] Pan, L., Lu, R., Zhu, Q., McGrath, J. M., and Tu, K. 2015. "Measurement of Moisture, Soluble Solids, Sucrose Content and Mechanical Properties in Sugar Beet Using Portable Visible and Near-Infrared Spectroscopy." Postharvest Biology and Technology 102: 42-50.

[11] Sun, D. W., ed.. 2010. Hyperspectral Imaging for Food Quality Analysis and Control. London: Academic.

[12] Camelo, A. F. L., Gómez, P. A., and Cacace, J. E. 1995. "Model for Describing Tomato Color Changes (cv. Tommy) during the Postharvest." In Congreso Argentino de Horticultura. Termas de Río Hondo: ASAHO. (in Spanish)

[13] Zenebon, O., Pascuet, N. S., and Tiglea, P. 2008. Physicochemical Methods for Food Analysis. São Paulo: Instituto Adolfo Lutz, 4. (in Portuguese)

[14] ElMasry, G., Kamruzzaman, M., Sun, D. W., and Allen, P. 2012. "Principles and Applications of Light Backscattering Imaging in Quality Evaluation of Agro-food Products: A Review." Critical Reviews in Food Science and Nutrition 52 (11): 999-1023.

[15] Nicolaï, B. M., Beullens, K., Bobelyn, E., Peirs, A., Saeys, W., Theron, K. I., and Lammertyn, J. 2007. "Non-destructive Measurement of Fruit and Vegetable Quality by Means of NIR Spectroscopy: A Review.” Postharvest Biology and Technology 46 (2): 99-118.

[16] Mishra, P., Herrero-Langreo, A., Barreiro, P., Roger, J. M., Diezma, B., Gorretta, N., and Lleó, L. 2015. "Detection and Quantification of Peanut Traces in Wheat Flour by Near Infrared Hyperspectral Imaging Spectroscopy Using Principal-Component Analysis.” Journal of Near Infrared Spectroscopy 23 (1): 15-22.

[17] Mencarelli, F., and Saltveit Jr, M. E. 1988. "Ripening of Mature-Green Tomato Fruit Slices.” Journal of American Society for Horticultural Science 113 (5): 742-5.

[18] Barankevicz, G. B., Novello, D., Resende, J. T. V., Schwarz, K., and Santos, E. F. 2015. "Physical and Chemical Characteristics of Tomato Hybrids Pulp during Frozen Storage.” Horticultura Brasileira 33 (1): 7-11. (in Portuguese)

[19] Ferreira, S. M. R., Quadros, D. A., Karkle, E. N. L., Lima, J. J., Tullio, L. T., and Freitas, R. J. S. 2010. "Postharvest Quality of Conventional and Organic Table Tomatoes.”
Ciência e Tecnologia de Alimentos 30 (4): 858-64. (in Portuguese)

[20] Ferreira, R. M. A., Lopes, W. A. R., Aroucha, E. M. M., Mano, N. C. S., and Sousa, C. M. G. 2012. "Physical and Chemical Characterization of Tomato Hybrids in Different Maturation Stages Produced in Baraúna, Rio Grande do Norte.” Revista Ceres 59 (4): 506-11. (in Portuguese)

[21] Odriozola-Serrano, I., Soliva-Fortuny, R., and Martín-Belloso, O. 2008. "Effect of Minimal Processing on Bioactive Compounds and Color Attributes of Fresh-Cut Tomatoes.” LWT_Food Science and Technology 41 (2): 217-26.

[22] Clément, A., Dorais, M., and Vernon, M. 2008. "Multivariate Approach to the Measurement of Tomato Maturity and Gustatory Attributes and Their Rapid Assessment by Vis-NIR Spectroscopy.” Journal of Agricultural and Food Chemistry 56 (5): 1538-44.

[23] Chitarra, M. I., and Chitarra, A. B. 1990. Post-harvesting of Fruits and Vegetables: Physiology and Handling. Lavras: ESAL/FAEPE. (in Portuguese)

[24] Camelo, A. F. L., and Gómez, P. A. 2004. "Comparison of Color Indexes for Tomato Ripening.” Horticultura Brasileira 22 (3): 534-7.

[25] Liu, C., Liu, W., Chen, W., Yang, J., and Zheng, L. 2015. "Feasibility in Multispectral Imaging for Predicting the Content of Bioactive Compounds in Intact Tomato Fruit.” Food Chemistry 173: 482-8.

[26] Clément, A., Dorais, M., and Vernon, M. 2008. "Non-destructive Measurement of Fresh Tomato Lycopene Content and Other Physicochemical Characteristics Using Visible-NIR Spectroscopy.” Journal of Agricultural and Food Chemistry 56 (21): 9813-8.

[27] Flores, K., Sánchez, M. T., Pérez-Marín, D., Guerrero, J. E., and Garrido-Varo, A. 2009. "Feasibility in NIRs Instruments for Predicting Internal Quality in Intact Tomato.” Journal of Food Engineering 91 (2): 311-8.

[28] Choudhary, R., Bowser, T. J., Weckler, P., Maness, N. O., and McGlynn, W. 2009. "Rapid Estimation of Lycopene Concentration in Watermelon and Tomato Puree by Fiber Optic Visible Reflectance Spectroscopy.” Postharvest Biology and Technology 52 (1): 103-9.

[29] Baiano, A., Terracone, C., Peri, G., and Romaniello, R. 2012. “Application of Hyperspectral Imaging for Prediction of Physico-Chemical and Sensory Characteristics of Table Grapes.” Computers and Electronics in Agriculture 87: 142-51. 